\title{
Design and Test of Additively Manufactured Check Valves and Pressurization Diffusers
}

\author{
Christopher C. Veto, Alex C. Cawthon, Victor J. Barackman, Alfredo Lopez, Martin E. Lozano, and \\ Gary D. Grayson
}

\begin{abstract}
Presented herein are metallic, additively manufactured hydraulic components comprising a set of competing pressurization diffusers as well as a set of competing relief check valves. The diffusers and check valves were grown out of a common material, Inconel 625. Then each set was tested for its cryogenic performance in cryogenic shock, flow testing, and vibration testing. This paper provides supporting evidence that metallic additive manufacturing components can be manufactured for use on launch vehicles, satellites, and re-entry vehicles. These hydraulic components - generalized for use with myriad aerospace, automotive, industrial, and seafaring applications - demonstrate a validation of metallic additive manufacturing as being at the forefront within the realms of both propulsion and materials science engineering.
\end{abstract}

Index Terms-Additive manufacturing, cryogenics, hydraulics, propulsion, materials, launch vehicles, re-entry, spacecraft, check valves, pressurization diffusers, advanced manufacturing.

\section{INTRODUCTION}

Apriori investigation of candidate AM (additive manufacturing) components within the Boeing Enterprise led to selection of pressurization diffusers and hydraulic check valves as the apropos demonstrators for metallic, AM capabilities onboard vehicles that include, but may not be limited to, launch vehicles, re-entry vehicles, aircraft, rotorcraft, automobiles, underwater vehicles and even industrial plants. The paper chronicles the design and testing of these cryogenic components. As such, this technical evaluation accentuates internal financial evaluations, which, together, motivate the desirability of implementing metallic additive manufacturing on modern product-lines. Inconel was selected over titanium (Ti-6Al-4V) due to its resistance to corrosion. Within Inconel, IN625 was selected over IN718 due to a greater strength-to-weight ratio in the absence of annealing IN718.

\section{APPROACH}

With chief interest in space exploration and the development of NASA's Space Launch System and the Defense Advanced Research Projects Agency (DARPA)'s Experimental Spaceplane (XS-1) program, a Creative Design Workshop led to a battery of over 20 pressurization diffuser concepts (used to evenly disseminate fluid within a fuel tank for even mixing) and over 20 check valve/relief valve

Manuscript received January 15, 2017; revised June 20, 2017.

C. C. Veto is with Boeing Research and Technology, Huntington Beach, CA 92647 USA (e-mail: christopher.c.veto@boeing.com). concepts (used as the safety valve to expel excess pressure within a pressurization line, or while checking in the reverse direction to prevent particulates from contaminating the purity of the propellant tank fuel, be it monomethylhydrazine (MMH), hydrazine, nitrogen tetroxide (NTO), liquid oxygen (LOx), liquid nitrogen (LN2), kerosene, xenon, lithium, etc. The AM check valves served as a benchmarking against commercial off-the-shelf (COTS) components that may be purchased from Anderson Greenwood or used in heritage space missions [1], [2], [3]. Pressurization diffusers were down-selected to two competing designs on the basis of diffusion performance, liquid impingement, mass, pressure drop, conventional manufacturing difficulty, conventional manufacturing part count, AM difficulty, and AM part count. The AM diffusers served as a benchmarking against a multi-part, sheet-metal diffuser [4]. The designs were then grown by an AM supplier using Inconel 625 powder. The check valves were down-selected to two competing designs on the basis of flow check performance, vibration tolerance, pressure drop, mass, conventional manufacturing difficulty, conventional manufacturing part count, AM difficulty, and AM part count. The check valves were grown by a second supplier, also using Inconel 625 powder. Both pressurization diffusers and both check valves were shipped to a testing supplier. Both pressurization diffusers and both check valves were tested in a random vibration test to simulate the launch environment. Both pressurization diffusers and both check valves were tested in thermal shock to simulate a cryogenic space environment. Both pressurization diffusers were tested with nitrogen gas for flow testing and with helium gas for shadowgraph flow visualization testing. Both check valves were tested with nitrogen gas for flow testing (including cracking pressure), for reverse-flow check and for both internal and external leak rate.

\section{DESIGN}

The designed diffusion horn is expressed in Fig. 1.

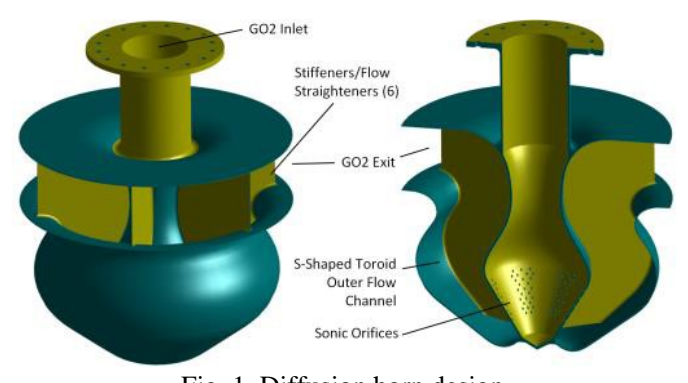

Fig. 1. Diffusion horn design.

Flow-through area is determined by the diamond-shaped 
flow-through holes which transition fluid from the internal chamber to the filling pot and then through the outlet. The designed inverted frustum is expressed in Fig. 2.

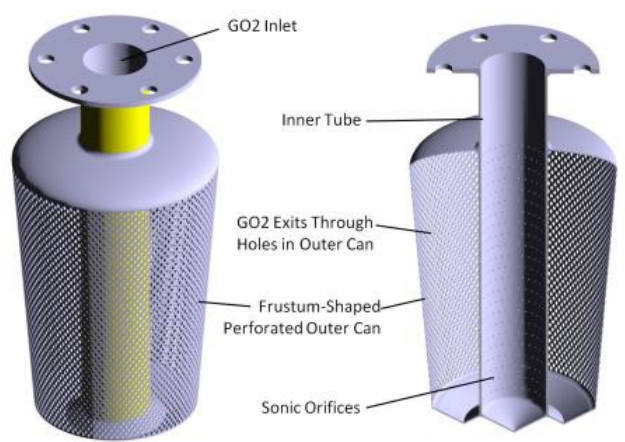

Fig. 2. Inverted frustum design.

Flow-through area is determined by (A.) a pattern of circular holes which transition fluid from the internal chamber to the filling pot and (B.) a pattern of diamond grid on the external shell which serves as the outlet. The inverted frustum's center tube orifice area is designed for choke flow conditions. Choked flow equations were applied such that.

$$
\dot{m}=C_{D} A P_{o} \sqrt{\frac{g}{z R T_{o}} \gamma\left(\frac{2}{\gamma+1}\right)^{\frac{\gamma+1}{\gamma-1}}},
$$

where mass flow rate is approximated for GO2 such that

$$
m_{O 2}=\frac{0.559 C_{D} A P_{O}}{\sqrt{T_{O}}}
$$

where mass flow rate is approximated for GH2 such that

$$
m_{H 2}=\frac{0.14 C_{D} A P_{O}}{\sqrt{T_{O}}},
$$

where $m$ is the mass flow rate, $C D$ is the discharge coefficient, $A$ is the area, $P_{O}$ is the upstream total pressure, $g$ is the acceleration of gravity, $\gamma$ is the specific heat ratio, $z$ is the compressibility factor, $T_{O}$ is the initial temperature, and $R$ is the gas constant [5]. The compressible flow equation may be re-expressed in terms of Mach number at the diffuser inlet such that

$$
\dot{m}=P_{o} A M \sqrt{\frac{k g_{c}}{R T_{o}}} \frac{1}{\left(1+\frac{\gamma-1}{2} M^{2}\right)^{\left(\frac{\gamma+1}{2(\gamma-1)}\right)}},
$$

where $M$ is the Mach number [17].

The outer holes of the diffuser are sized using the sub-sonic flow equation such that

$$
\dot{m}=P_{O} A M \sqrt{\frac{2 g_{c} \gamma}{(\gamma-1) R T}\left[\left(\frac{P_{2}}{P_{1}}\right)^{\frac{2}{\gamma}}-\left(\frac{P_{2}}{P_{1}}\right)^{\frac{\gamma+1}{\gamma}}\right]},
$$

where $P_{1}$ is the pressure between the inner cylinder and the outer shell, and $P_{2}$ is the pressure just outside the diamond-pattern holes of the outer shell.

To assess the performance of the diffusers, the diffusers were modeled at half-scale in FLOW-3D as axi-symmetric, compressible flow models. Models were ran to two seconds simulation time at half- scale. Figs. 3.1-3 depict the $K-\boldsymbol{\omega}$, RNG (renormalization group), and large eddy CFD results for the simulation of the diffusion horn.

Fig. 4 depicts the K-epsilon turbulence model for the final iteration of the pressurization diffuser.

Fig. 5 depicts the CFD model results for the inverted frustum in three loading accelerations.

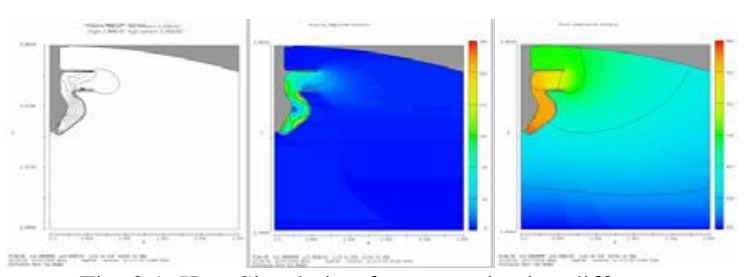

Fig. 3.1. K- $\boldsymbol{\omega}$ Simulation for pressurization diffuser.

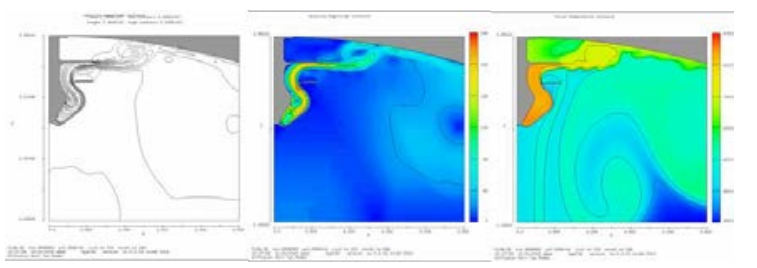

Fig. 3.2. RNG Simulation for pressurization diffuser.

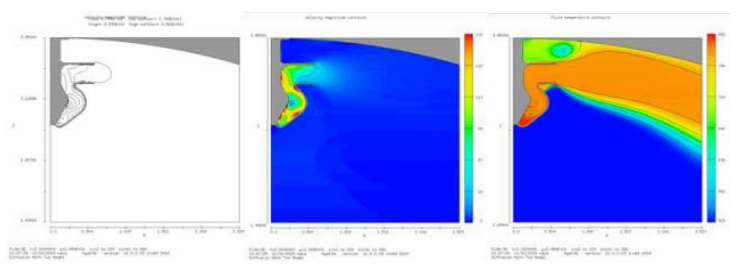

Fig. 3.3. Large Eddy simulation for pressurization diffuser.

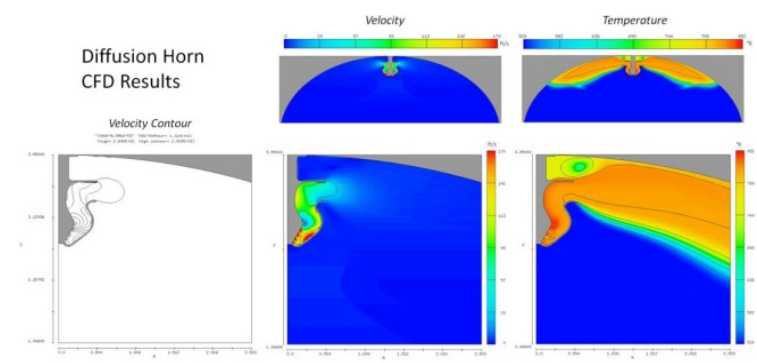

Fig. 4. Turbulence model for final diffusion horn iteration.

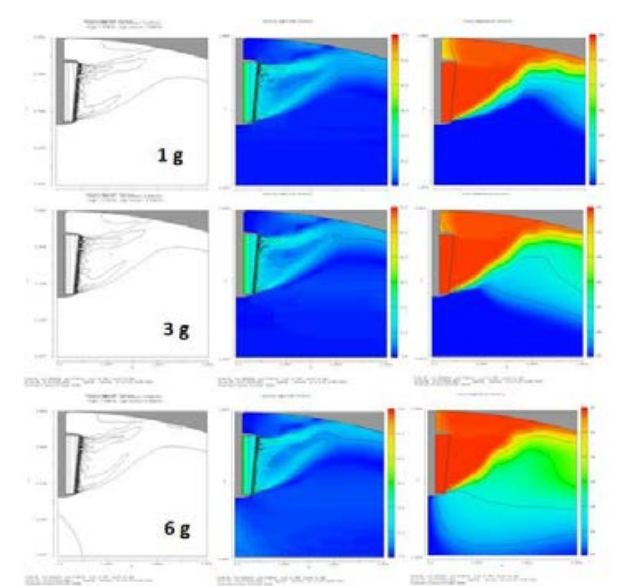

Fig. 5. FLOW-3D model of inverted frustum $1 \mathrm{~g}, 3 \mathrm{~g}$, and $6 \mathrm{~g}$ loading accelerations.

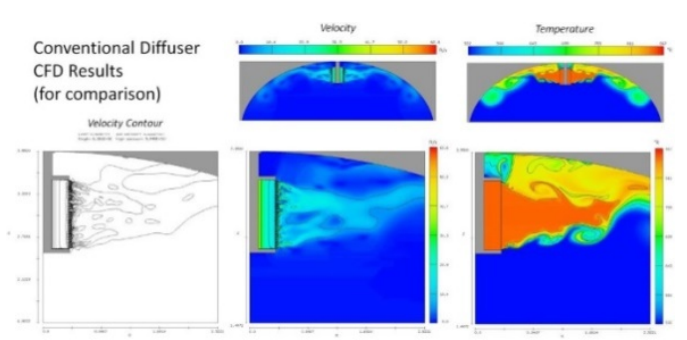

Fig. 6. FLOW-3D simulation of conventional diffuser. 
The Prandtl mixing length model is one of the earliest attempts to describethree-dimensional turbulence effects. It is the least complex model, and is no longer widely used. FLOW-3D includes it mainly for its usefulness in academic studies. The so-called one-equation model is also an early effort to represent turbulence. It calculates time-averaged turbulent kinetic energy $k$ and requires a known turbulent mixing length $L T$ at all locations. Since $L T$ is not usually known ahead of time, the one- equation model is not suitable for modeling complex flows.

The standard k- $\varepsilon$ model (Harlow \& Nakayama 1967) is a two-equation model that calculates both turbulent kinetic energy, $k$ and dissipation rate, $\varepsilon$, and dynamically finds the turbulent mixing length $L T$ [6]. It is an industry standard, and has been found useful for representing a wide range of flows (Rodi 1980) [7].

The renormalized group (RNG) $k-\varepsilon$ model (Yakhot \& Orszag 1986, Yakhot \& Smith 1992) is a more robust version of the two-equation $k-\varepsilon$ model, and is recommended for most industrial problems [8], [9]. It extends the capabilities of the standard $k-\varepsilon$ model to provide better coverage of transitionally turbulent flows, curving flows, wall heat transfer, and mass transfer.

The $k-\omega$ two-equation model (Wilcox 1988, 1998, 2008) defines the second variable not as turbulent dissipation $\varepsilon$ but as $\omega \equiv \varepsilon / k$ (Kolmogorov 1942) [10]-[13]. Wilcox has improved upon the $k-\omega$ two-equation model since 1988. In 1998 he introduced new coefficients that significantly improved the accuracy of the model for free shear flows. The $k-\omega$ two-equation model in FLOW-3D is thus suitable for modeling free shear flows with streamwise pressure gradients like spreading jets, wakes, and plumes.

The LES (large eddy simulation) model does not use scalars to represent average turbulent kinetic energy, but rather resolves most of the turbulent fluctuations directly. It requires much finer mesh resolution than the two-equation models and provides more extensive statistics of the turbulent flow. The 2-D depth-averaged shallow water turbulence model assumes a logarithmic fully turbulent velocity. The first option assumes a constant drag coefficient $C D$, which may be spatially varied. The second 2-D depth-averaged shallow water turbulence model makes the drag coefficient $C D$ a dynamic function of fluid depth and spatially variable surface roughness.

The guidevane check valve design is shown in Fig. 7.



Fig. 7. Guidevane valve design.

Wall thickness was determined using the Modified-Goodman equations from Shigley's and verified with the thick-wall approximation [14]. The spring was sized using Hooke's Law to achieve a target cracking pressure of 5 psig. The stacked disk valve design is shown in Figure 8.

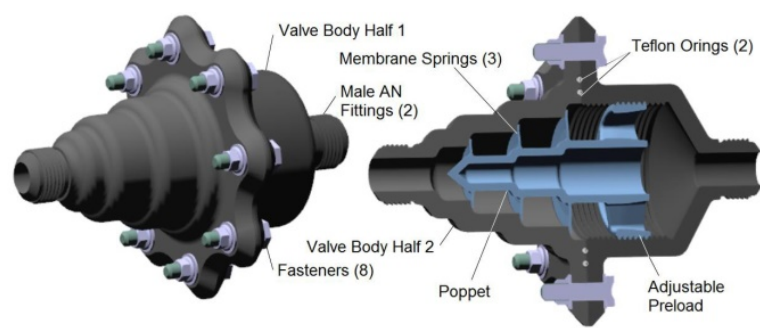

Fig. 8. Stacked disk valve design.

Like the guidevane valve, the valve housing was sized with the Modified-Goodman equations from Shigley's and verified with the thick-wall approximation [14]. The disks on the poppet assumed clamped-free boundary conditions and were sized for deflection using the Roark's equations for circular disks. Equation 1 exhibits the disk deflection equation, such that

$$
y_{a}=M_{r b} \frac{a^{2}}{D} C_{2}+Q_{b} \frac{a^{3}}{D} C_{3}-\frac{q a^{4}}{D} L_{11},
$$

where ya is the deflection at the tip; Mrb is the moment applied to the clamped connection to the center pylon; $\mathrm{a}$ is the outer diameter of the disks; $D$ is the plate constant; and $Q b$, $C_{2}, C_{3}$, and $L_{11}$ are defined according to according to Roark's [15].

Pre-loading equations were applied to determine the proper torque on the fasteners for both valves; the fasteners were tightened in a star pattern.

Inlet area and pressure drop were designed using the mass flow equation

$$
\dot{m}=c_{d} A_{o} \sqrt{\frac{2 g_{c}}{144} \rho \Delta P},
$$

TABLE I: ESTIMATED PRESSURE DROP

\begin{tabular}{|c|c|c|c|c|} 
Valve Name & A_2(H20) & C_d & Min Line Velocity & Max Line Velocity \\
\hline Guidevane Valve & 0.20 & 0.81 & 5.00 & 20.00 \\
\hline Stacked Disk Valve & 0.20 & 0.61 & 5.00 & 15.00 \\
\hline & in^2 $^{\wedge}$ & N/A & $\mathrm{fps}$ & $\mathrm{fps}$
\end{tabular}

\begin{tabular}{c||c|c|c|c|c|c|c|c}
\hline Valve Name & Temp (H2) & Pressure (H2) & Density (H2O) & Min M_dot & Max M_dot & Delta P Min & Delta P Max \\
\hline Guidevane Valve & 68.00 & 114.70 & 62.34 & 0.42 & 1.70 & 0.26 & 4.10 \\
\hline Stacked Disk Valve & 68.00 & 114.70 & 62.34 & 0.42 & 1.27 & 0.45 & 4.07 \\
\hline & F & PSIA & $\mathrm{Ibm} / \mathrm{ft} \wedge 3$ & $\mathrm{lbm} / \mathrm{s}$ & $\mathrm{lbm} / \mathrm{s}$ & PSIG & PSIG
\end{tabular}

where $\dot{m}$ is the mass flow; $C_{d}$ is the coefficient for square edge, sharp-edge (and equivalent sharp edge orifice diameter (ESEOD)), and curved edge; and Ao is the orifice area [16]. Pressure drop was roughly approximated pursuant to Table I.
The National Institute of Standards and Technology (NIST)'s Reference Fluid Thermodynamic and Transport Properties Database (REFPROP) was used for density calculation. 


\section{RESUlTS}

Vibration tests were conducted on both pressurization diffusers and both check valves. Since all four components survived vibration tests, data is provided solely on the stacked disk check valve, which exhibited potential frequency modes. Table II contains the breakpoints for acceleration spectral density of the vibration tests on both of the check valves.

\begin{tabular}{|c|c|c|c|c|c|c|}
\hline \multicolumn{7}{|c|}{$\begin{array}{l}\text { TABLE II: AM CHECK VALVE VIBRATION TEST SPECTRAL DENSITY } \\
\text { BREAKPOINTS }\end{array}$} \\
\hline \multicolumn{7}{|l|}{ Breakpoint table } \\
\hline Frequency & $\mathrm{G}^{2} / \mathrm{Hz}$ & $\mathrm{dB} /$ Octave & Toles & & Abort & \\
\hline $20 \mathrm{~Hz}$ & 0.1 & 6.702 & +1.2 & -1.2 & +1.5 & -1.5 \\
\hline $120 \mathrm{~Hz}$ & 5.4 & 0 & +1.2 & -1.2 & +1.5 & -1.5 \\
\hline $180 \mathrm{~Hz}$ & 5.4 & -9.852 & +1.2 & -1.2 & +1.5 & -1.5 \\
\hline $220 \mathrm{~Hz}$ & 2.8 & 0 & +1.2 & -1.2 & +1.5 & -1.5 \\
\hline $480 \mathrm{~Hz}$ & 2.8 & -8.962 & +1.2 & -1.2 & +1.5 & -1.5 \\
\hline $1000 \mathrm{~Hz}$ & 0.3149 & & +2.5 & -2.5 & +3 & -3 \\
\hline $1000 \mathrm{~Hz}$ & 0.3149 & -8.961 & +2.5 & -2.5 & +3 & -3 \\
\hline $2000 \mathrm{~Hz}$ & 0.04 & & & & & \\
\hline
\end{tabular}

Table III contains the duration of the vibration tests applied to the pressurization diffusers.

TABLE III: AM CHECK VALVE VIBRATION TEST SCHEDULE Test level schedule:

$\begin{array}{llll} & \text { Duration } & \text { Level } & \\ \text { 1) } & 0: 00: 05 & -12 \mathrm{~dB} & \\ \text { 2) } & 0: 00: 05 & -9 \mathrm{~dB} & \text { (MD) } \\ \text { 3) } & 0: 00: 05 & -6 \mathrm{~dB} & \text { (MD) } \\ \text { 4) } & 0: 00: 03 & -3 \mathrm{~dB} & \text { (MD) } \\ \text { 5) } & 0: 00: 10 & 0 \mathrm{~dB} & \text { (MD) } \\ \text { ** } & \text { Test started Jun 29, 2016 13:08:41, running for 0:01:03 } \\ \text { ** } & \text { Current level: } 5 \text {, running at } 0 \mathrm{~dB} \text { for } 0: 00: 10 \text { of } 0: 00: 10\end{array}$

For all four devices, nine channels were used to measure response to random vibration: channels 1,4 and 7 in the $\mathrm{x}$-axis; channels 2, 5 and 8 in the y-axis; and channels 3, 6, and 9 in the z-axis. Trials two through five use the MD (memorized drive) function within the shake table's Vibration Research VR 9500 vibration controller, which is a benchmarking against the drive signal calculated at $-12 \mathrm{~dB}$. The MD function allows for more precise response to input control as well as faster test scheduling.

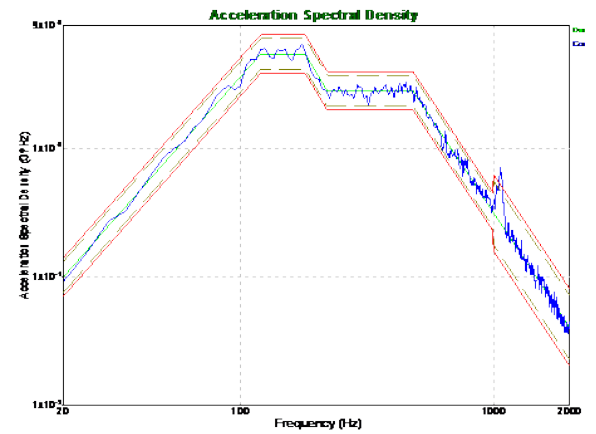

(A) Axial axis.

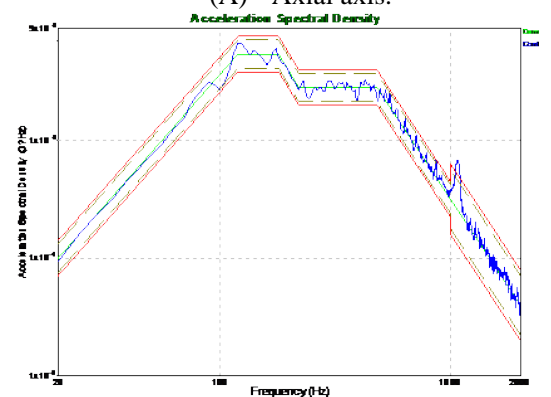

(B) Radial axis.

Fig. 9. Commanded spectral density of stacked disk valve.
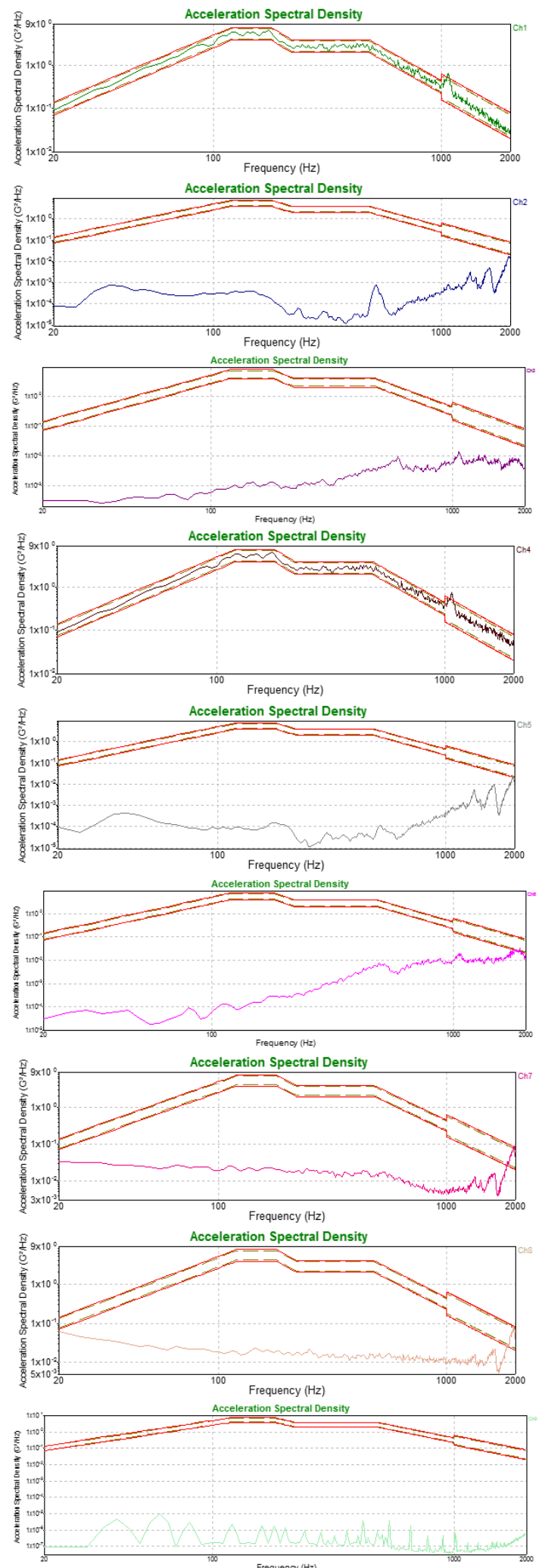

Fig. 10. Accelerometer data for stacked disk valve axial vibration test.

Fig. 9 provides the commanded spectral density for the axial vibration test of the stacked disk valve.

The red lines in Fig. 9 illustrate the desired band of commanded acceleration spectral density. This band is re-printed on Figs 10 and 11 to provide a frame of reference for response of the test article to commanded vibration loading.

The axial vibration test results for the stacked disk valve are provided in Fig. 10 according to the aforementioned 
channel allocation.
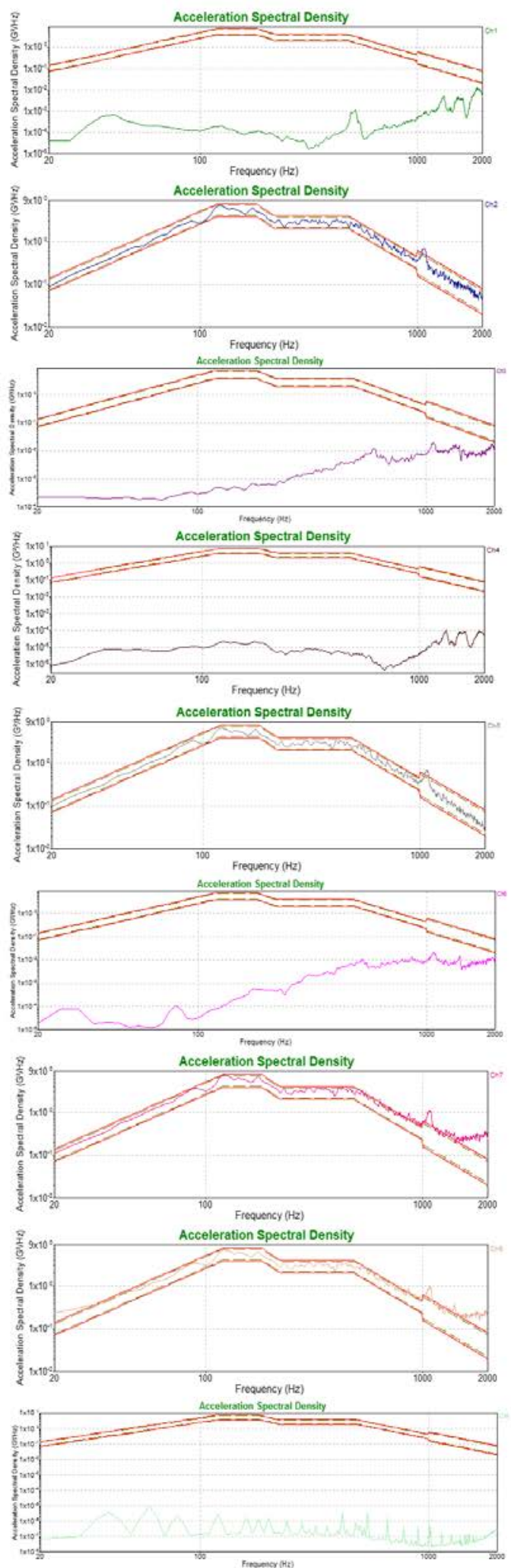

Fig. 11. Accelerometer data for stacked disk valve radial vibration test.

The radial vibration test results for the stacked disk valve are provided in Fig. 11 according to the aforementioned channel allocation.

Fig. 12 shows the shadowgraph image of the helium flow test for both the diffuser horn and the inverted frustum, juxtaposed with results from the FLOW-3D simulation work of the design phase. Note the difference in fluid, upstream pressure and temperature.
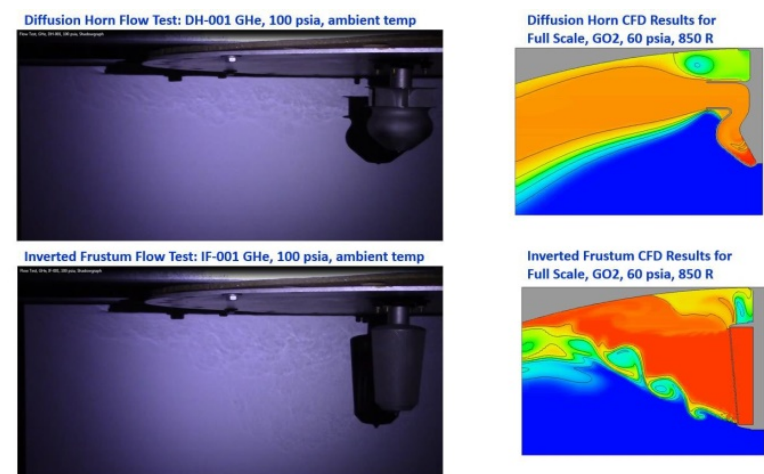
Inverted Frustum CFD Results for
Full Scale, G02, 60 psia, 850 R

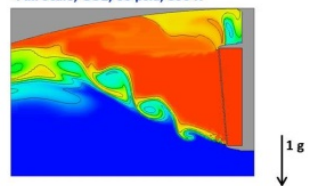

Fig. 12. Shadowgraph images of diffusion horn and inverted frustum during helium flow test.

Fig. 13 shows a sampling of the nitrogen flow test at 80 psia for both the diffuser horn and the inverted frustum.
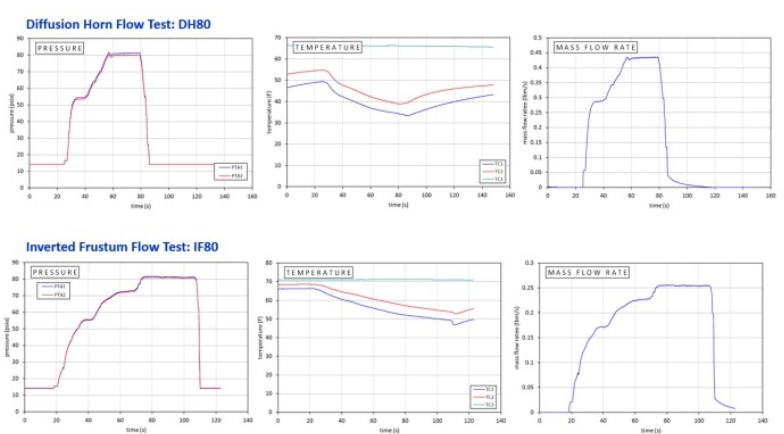

Fig. 13. Nitrogen flow test data for pressurization diffusers

The check valves were tested for cracking pressure using gaseous nitrogen. Fig. 14 depicts the cracking pressure for the guidevane valve.

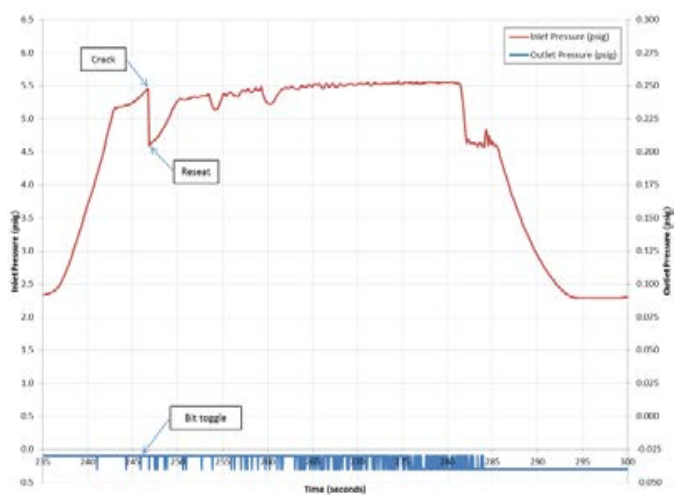

Fig. 14. Cracking pressure test for guidevane check valve.

Fig. 15 depicts the cracking pressure test for the stacked disk valve.

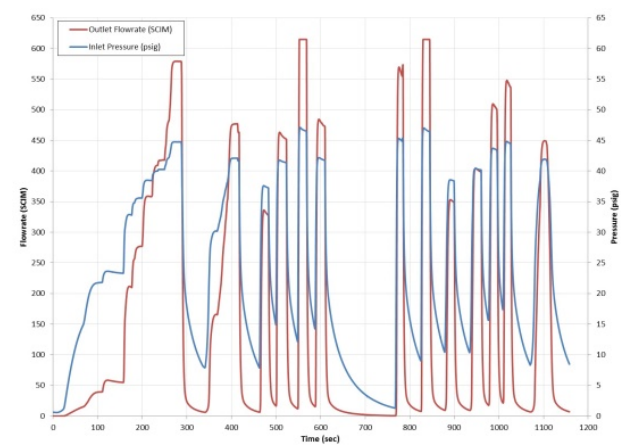

Fig. 15. Cracking pressure test for the stacked disk check valve. 
Fig. 16 depicts the cracking pressure test for the stacked disk valve in a parametric plot.

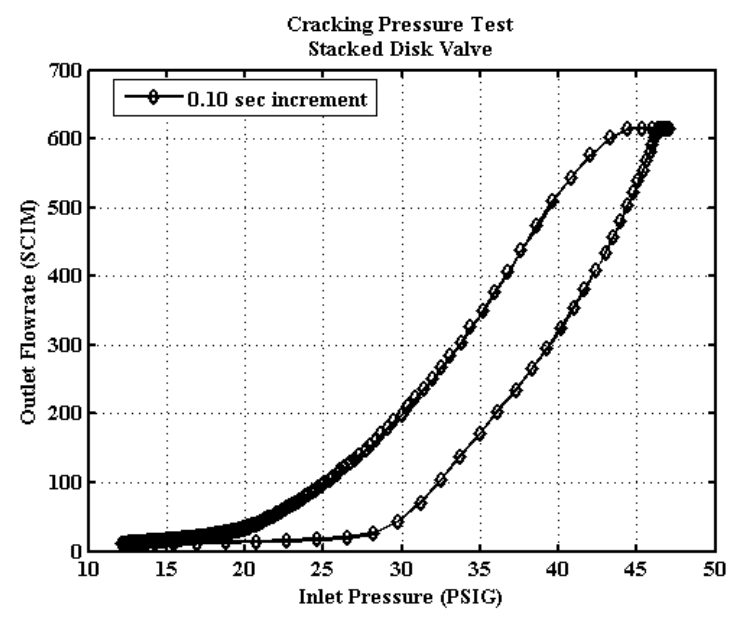

Fig. 16. Stacked disk valve cracking pressure test.

Opening the valve may be characterized by the fourth-order regression of Equation 8, such that

$$
\begin{aligned}
\dot{m}_{\text {open }}=- & 0.0011 x^{4}+0.1423 x^{3}-5.6626 x^{2}+\ldots 88.8446 x- \\
& 464.8955 .
\end{aligned}
$$

Closing the valve may be characterized by the regression of Equation 9, such that

$$
\begin{gathered}
\dot{m}_{\text {close }}=-0.0023 x^{4}+0.2499 x^{3}-9.0344 x^{2}+\ldots 143.2156 x \\
-842.887 .
\end{gathered}
$$

Fig. 17 depicts the data collected for the water flow test of the guidevane check valve.

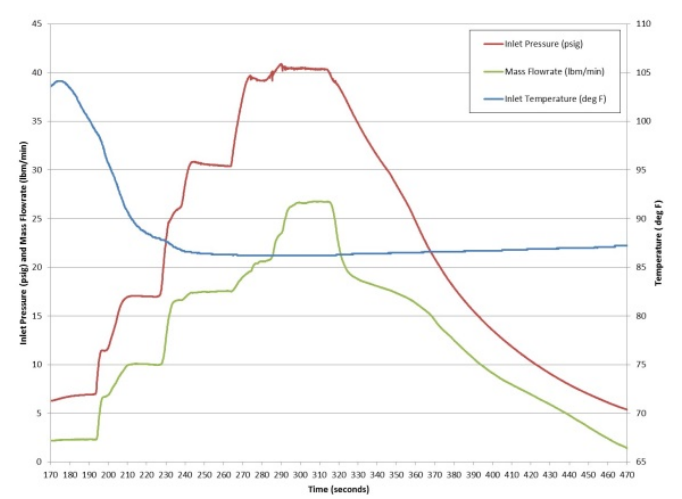

Fig. 17. Guidevane valve water flow test.

Fig. 18 depicts the data collected for the water flow test of the stacked disk check valve.

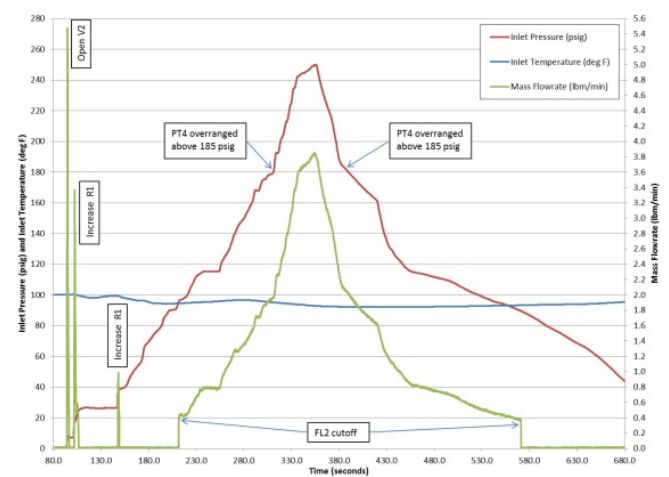

Fig. 18. Stacked disk valve water flow test.

\section{ANALYSIS}

We can see from the turbulence models that the inverted frustum appears to exhibit a greater performance in terms of distributing the incoming fluid towards the ceiling of the fuel cell. The conventional diffuser, shown in Fig. 6, simply directs the mixing outwards; whereas the inverted frustum, shown in Fig. 5, directs the high-temperature fluid upwards in $1 \mathrm{~g}, 3 \mathrm{~g}$ and $6 \mathrm{~g}$ accelerations.

Fig. 4 reveals that the diffuser horn performs slightly more poorly in terms of vectoring the high- temperature fluid towards the ceiling of the fuel tank than the inverted frustum. However, it can be seen that the diffuser horn does perform well in terms of reducing the flow velocity of the fluid within the diffuser horn due to viscous shear and mixing as the fluid flows along the curves of the outer reservoir, smashing into the side walls, before exiting the diffuser horn and entering the larger fuel tank.

Perhaps the ideal diffuser would be a combination of both diffusers, a diffuser in the shaping of the diffuser horn that had an external, diamond grid at the exit, similar to the inverted frustum, which directed fluid up towards the ceiling of the tank.

Fig. 12 shows images of the diffusers during Shadowgraph testing. Helium gas was used in order to provide contrast against the ambient nitrogen fluid. The helium gas is clearly directed upwards towards the ceiling. Note the conflated differences betwixt the Shadowgraph flow test and the turbulent models: the subscale shadowgraph used a more cost-affordable horizontal ceiling; whereas the full-scale turbulent model used the square-root tank wall boundary condition. Further, the Shadowgraph flow test implemented an ambient pressure of 100 psia; whereas the turbulent model implemented an ambient pressure of 60 psia. The shadowgraph implemented a gaseous helium fluid; whereas the turbulent models implemented a gaseous oxygen fluid. The shadowgraph assumed an ambient temperature of approximately $525 \mathrm{R}$; whereas the turbulent model assumed an ambient temperature of 850 R. Finally, minor differences may include, but not be limited to, the $250 \mu$ in Ra surface finish within the pressurization diffusers, fluid circulation within the test chamber, clogged holes inside the inverted frustum diffuser, the tear on the vertical wall of the diffuser horn, effects of chambering within the diffuser horn, alignment and misalignment of pin-holes and diamond holes in the inverted frustum, etc.

The nitrogen flow test for the pressurization diffusers allowed each to be compared. Observing Fig. 13, at 80 psia, the diffuser horn had a much greater mass flow rate (approximately $0.44 \mathrm{lbm} / \mathrm{sec}$ ) than the mass flow rate of the inverted frustum (approximately $0.25 \mathrm{lbm} / \mathrm{sec}$ ). There is a choking effect as the fluid passes through the pin-holes in the inner-cylinder of the inverted frustum and then another resistance as the fluid passes through the diamond holes in the outer cylinder of the inverted frustum. Inspection of the frustum orifice holes indicated a reduction of effective flow area, resulting in a higher overall resistance as indicated by flow data. By comparison, while the diffuser horn also has a diamond grid of sonic orifices, leading from the inner cylinder to its outer cylinder, the fluid is able to more freely exit the S-shaped toroid of the outer cylinder without a secondary flow obstruction. Perhaps design of the inverted 
frustum could be modified such that the sonic orifices of the inner tube are properly sized to account for the "roundness" of the orifice holes by AM processes.

All four components survived cryogenic shock testing. Type-E thermal couples were attached to all four devices. A side-brew of liquid nitrogen served as a reference point to calibrate the thermal sensing of the liquid hydrogen which engulfed the components.

All four components survived vibration testing.

Prior to vibration test of the diffuser horn, there was a tear of approximately $1.636 \mathrm{~cm}$ in length on one of the vertical walls. The tear was marked prior to test. After the test, it was clear that there was no propagation in the tear, which is promising from the perspective of stress-fracture propagation during nominal operation. The inverted frustum yielded no deformation during vibration testing. The axial and radial acceleration spectral density data (not shown) indicate that no unordinary or resonant frequencies were observed under the applied spectral densities.

For the check valves, the most damage-inducing vibration test was that in which each valve's axi-symmetric z-axis was aligned with the plunging of the vibration table. For the guidevane valve, the valve repeatedly transitioned between open and closed position, implying that the tip of the valve was pounding against the valve housing. Post-test, inspection revealed a pitting on the tip of the poppet head as well as some abrasive marks in the valve housing. A flow test after the vibration test indicated that the guidevane valve would not seal, likely due to either the pitting or a misalignment of the guidevane poppet during vibration. Achieving perfect concentricity of a conical poppet with a conical orifice is rather taxing. A future design iteration to correct for this dilemma could include embedding an O-ring land within either the conical tip of the guidevane poppet or within the conical orifice of the guidevane housing, such that a Teflonor Kel-F O-ring could be installed.

For the stacked disk valve, there were two concerns: first, the stacked disk valve poppet had the ability to rotate during vibration pressure, thus alleviation the intended cracking pressure (and cracking function) of the valve; second, the ability for the disks to flap against the shelving of the stacked disk housing. For the first concern, a design iteration could be to locate the threads on the same housing half as the shelves. While there was a C-ring installed in an attempt to lock in the rectilinear poppet location, it was rather difficult to pre-set the C-ring in the desired location. A tuning probe (approximately $1.885 \mathrm{~cm}$ in diameter) was also used to rotate the poppet within the assembly in order to achieve a desired cracking pressure during flow tests, yet it was unclear whether the tuning probe slipped against the inner wall of the popper during rotation, leading to an unknown poppet location. For the second concern, disassembling the valve after vibration testing revealed burnishing marks on the poppet disks. If a lapping process is used in the future to fine-tune the seal between the disks and the housing shelves, the benefits may be altogether negated by such burnishing. Thus, two solutions are proposed. The poppet could be manufactured from a separate material than the IN625 metal housing. The poppet could be mold-injected with Kel-F or could be printed with malleable acrylonitrile-butadiene styrene (ABS) or polylactic acid (PLA). This hybrid metal-plastic valve would function quite well and would be quite feasible with existing technology. The test supplier believes in the resiliency of ABS and PLA in the cryogenic environment based on experience. The second solution would be similar to the solution for the guidevane valve poppet: embed an O-ring land within the disks of the stacked disk poppet to install a malleable, Kel-F O-ring. The dilemma with the second solution lies in that the disks of the poppet may have to be thickened; however, the thickness of the disks was sized per the Roark's equations for a target cracking pressure below 20 psig [15]. Volumetrically thickening the disks to account for a Teflon O-ring land near the edge would implicate swapping the IN625 for a more malleable material (e.g., Al10SiMg), but if swapping the material of the poppet is warranted, then the most affordable and most technically practical solution is attempting a plastic poppet.

Similar to the pressurization diffusers, the axial and radial acceleration spectral density data for the guidevane valve indicate that no unordinary or resonant frequencies were observed under the applied spectral densities of the guidevane valve (not shown). However, the axial and radial acceleration spectral density data (Figs. 10-11) for the stacked disk valve exhibit a potential excitation of frequency modes around $700 \mathrm{~Hz}$ (see Ch. 2 and 7 in Fig. 10), $1100 \mathrm{~Hz}$ (see Ch. 7 and 8 in Fig. 11), and 2000 Hz (see Ch. 7 in Fig. 10). Though noteworthy, the valve still survived, and modal oscillations may potentially be attributed to the test fixture used to clamp the stacked disk valve.

For the functional capability of the check valves, gaseous nitrogen was used to observe their cracking pressures so as to validate the designed cracking pressures - using Hooke's law in the case of the guidevane valve or using Roark's equations in the case of the stacked disk valve. Fig. 24 depicts the cracking pressure for the guidevane valve at approximately 5 psig, which was roughly half of the intended design. One explanation could be that the spring constant was provided during vertical operation, whereas the valves were tested in the horizontal position negating the influence of gravity on the spring constant. A recherché feature of the guidevane poppet included a step that allowed for the inclusion of shims (flat disks) that could be inserted over the central pylon in the guidevane valve to further compress the spring in the nominally closed position and increase the cracking pressure. Fig. 15 depicts the cracking pressure for the stacked disk valve. The stacked disk valve appears to crack at around 30 psig. One of the interesting notations of tuning the stacked disk valve for cracking was the heightened sensitivity of cracking pressure to the rotation of the poppet, due to the stiffness of the IN625 material. In calculating the deflection of the disks, a stiffness of 30.1 Msi was assumed [17]. Tip displacement of the disks was calculated by rectilinear translation of the poppet. The spacing between threads indicated the degree of rotation to achieve a desired poppet translation that corresponded with a target cracking pressure. Fig. 16 depicts one hysteresis cycle of a nitrogen flow test. The inflection point on the lower curve indicates the opening of the valve at approximately 26 psig. The concavity of the curve suggests the non-linear effect of the fluid sequentially cracking each disk and traveling from upstream to the first chamber, followed by the second chamber and eventually out 
the exit. The separation between the opening and closing curves may indicate a stick- friction that must be overcome to crack each of the disks. During the transition from the closed to the cracked regimes, a singing noise was heard, which was hypothesized as the disks chattering against the shelves. A fourth-order regression is provided for opening (Equation 8) and for closing (Equation 9) of the valve.

Water flow testing of the guidevane valve and the stacked disk valves is depicted in Fig. 17 and Fig. 18, respectively. The maximum flow rate for the guidevane valve was observed at approximately $26 \mathrm{lbm} / \mathrm{min}$ with an upstream pressure of 40 psig. The maximum flow rate for the stacked disk valve was observed at approximately $3.8 \mathrm{lbm} / \mathrm{min}$ with an upstream pressure of 190 psig. At maximum flow rate, video footage shows that the guidevane valve exudes a turbulent flow, whereas the stacked disk valve exudes a more laminar flow. The two chambers between the three disks of the stacked disk valve creates a choking effect. Further analysis of the mixing between the chambers of the stacked disk valve could include a turbulent FLOW-3D model, the installation of pressure taps in the housing of the valve to provide data for each of the chambers, and/or the use of flow visualization [18].

\section{CONCLUSION}

An expansion of the project includes X-ray visualization of the devices in operation [18]. Thermal deformation software may be used to compensate warping in future builds [19], [20]. Our printers may be tuned, in terms of parameters of cross-hatch, scan speed, and laser power to minimize internal voids [21]. A variety of surface smoothing techniques may be tested. Generally, the test results were promising: the cryogenic components survived shock test and vibration test. Functionally, the pressurization diffusers directed the gaseous helium towards the top of the tank dome, and the check valves demonstrated an acceptable cracking pressure. Future design iterations are spread between this manuscript and pending invention disclosures. Supplier capability upgrades and enterprise strategy are suggested in an internal cost analysis. The design and test of the AM IN625 components points to the feasibility of AM IN625 units for product-line cryogenic, hydraulic and/or propulsion applications.

\section{ACKNOWLEDGEMENT}

Ineffable gratitude is owed towards Program Management for completing the program ahead of schedule and under budget. Tremendous support was provided by Jackie Louie and Supplier Management in negotiating and definitizing supplier contracts. Lean+ principles were applied by Kristen Monroe and Finance to augment program efficiency. The test suppliers at Innovative Engineering Solutions proficiently achieved all deliverables, and it was a great pleasure to work with them, including Shane Johnson for vibration testing. Great thanks is owed to the Boeing Phantom Works, including Henry Rodriguez, and Boeing Research \& Technology organizations for innovatively collaborating on design and analysis.
This research was developed with funding from the Defense Advanced Research Projects Agency (DARPA). The views, opinions and/or findings expressed are those of the authors and should not be interpreted as reflecting the official views or policies of the Department of Defense or the U.S. Government.

\section{REFERENCES}

[1] Harlow, H. Francis and P. I. Nakayama, Transport of Turbulence Energy Decay Rate. Linthicum Heights, Md.: NASA Center for AeroSpace Information, 1990

[2] Rodi, "Wolfgang turbulence models and their application in hydraulics: A state of the art review," The Netherlands: International Association for Hydraulic Research, 1984.

[3] Yakhot, Victor and S. A. Orszag, "Renormalization group analysis of turbulence. I. basic theory." Journal of Scientific Computing, vol. 1, no.1, pp. 3-51, 1986.

[4] Yakhot, Victor and L. M. Smith, "The renormalization group, the $\varepsilon$-expansion and derivation of turbulence models." Journal of Scientific Computing, vol. 7, no. 1, pp. 35-61. 1992.

[5] Wilcox, C. David, "Reassessment of the scale-determining equation for advanced turbulence models," AIAA Journal, vol. 26, no. 11, 1299-1310, 1988.

[6] Wilcox and C. David, Turbulence Modeling for CFD., La Cãnada, Calif: DCW Industries, 1998.

[7] D. C. Wilcox, "Formulation of the K Omega turbulence model revisited," AIAA Journal, vol. 46, no. 11, pp. 2823-2847, 2008.

[8] A. N. Kolmogorov, Equations of Turbulent Motion of an Incompressible Fluid, Izv. Akad. Nauk SSSR, 1942.

[9] Roark, J. Raymond, and W. C. Young, Roark's Formulas for Stress and Strain, New York: McGraw-Hill, 1989.

[10] Budynas, G. Richard, J. K. Nisbett, and J. E. Shigley, Shigley's Mechanical Engineering Design, New York: McGraw-Hill, 2011.

[11] Crane Co., Flow of Fluids Through Valves, Fittings, and Pipe, p. 410, King of Prussia, PA, 1998.

[12] Heindel and J. Theodore, "A Review of X-Ray Flow Visualization Applications to Multiphase Flows.” Iowa State University. Digital Repository @ Iowa State University. 22 Jul. 2011.

[13] Rossmann, Christian, "Modeling and Simulation for Additive Manufacturing,” (Apr. 2016). [Online]. 6 Available: http://3dprintingsimulation.blogspot.com/2016/04/simulation-of-ther mal-stresses-during_6.html

[14] Sett and Subham. "Can Simulation Help Advance Additive Manufacturing Technology?” (2016). [Online]. Available: http://www.linkedin.com/pulse/can-simulation-help-advance-additive -manufacturing-technology-sett.

[15] Flow Science, "FLOW-3D 11," [Online]. Available: https://www.flow3d.com/home/products/flow-3d/flow-3d-v11.

[16] Special Metals, “INCONEL alloy,” (Aug. 13, 2013). [Online]. 625. Available:

http://www.specialmetals.com/assets/documents/alloys/inconel/incon el-alloy-625.pdf

[17] Shapiro and H. Ascher, "The dynamics and thermodynamics of compressible fluid flow,” New York: Ronald Press Co., 1953.

[18] Anderson Greenwood POPRV CATALOG. Series 200, 400, 500, 700 and 800. Pentair. ANGMC-0243-US-1302. (2013). [Online]. Available: http://www.pentair.com/valves

[19] Stephens and R. Jonathan, "Cryogenic propellant tank sub-surface pressurization with bang- bang control," in Proc. eCryo Industry Workshop, 2016.

[20] J. D. Albright et al., "Lessons learned from the design, certification, and operation of the space shuttle integrated main propulsion system (IMPS)," AIAA 2011-5838 in Proc. 47th AIAA/ASME/ASEE Joint Propulsion Conference \& Exhibit, San Diego, California, July 31August 3, 2011.

[21] M. J. Barrett, G. S. Aber and T. W. Reith, "Space shuttle simplified $\mathrm{LO}_{2}$ check valve development tests," Journal of Propulsion and Power, vol. 1, no. 1, p. 324. 1995.

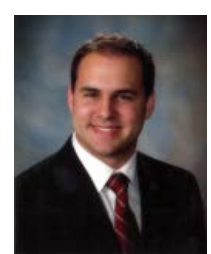

Christopher Veto holds two engineering degrees: a B.S. in mechanical engineering and materials science from Duke University and an M.S. in mechanical and aerospace engineering from Princeton University.

He has eight patents which are navigating the United States Patent and Trademark Office. 
Alexander Cawthon earned his mechanical engineering degree from the California State Polytechnic University, Pomona, California.

He is a project engineer with Innovative Engineering Solutions, Murrieta, California where he manages testing of aerospace components with an emphasis in cryogenic temperatures.

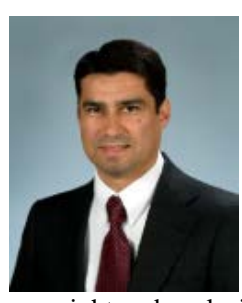

Martin Lozano has supported a variety of United States aerospace vehicle and technology programs for 33 years in the areas of cryogenic and storable propulsion system development. He received a B.S. degree in mechanical engineering from Stanford University and is currently serving as technical lead Engineer (TLE) under the Exploration Upper Stage (EUS) Program for the Propulsion Subsystem area. His current responsibilities include technical oversight and analysis for the development of the Main Propulsion Systems (MPS) for the Space Launch System (SLS) Core Stage and the EUS. Martin is a boeing associate technical fellow specializing in propulsion and cryogenic technologies and was a pioneer in the development and testing of large scale propellant densification technologies for which he holds several US patents. Throughout his career he has supported a number of other programs including the DARPA XS-1, NASA Ares I Upper Stage, the High Altitude High Endurance (HALE) hydrogen-fueled airplane, Delta IV Common Booster Core (CBC), Space Shuttle Orbiter, Shuttle Centaur and the National Aerospace Plane (NASP). His primary expertise includes thermodynamic analysis of sub-critical tank pressurization subsystems and high pressure gas distribution systems, as well as cryogenic fluid storage and transfer systems. His interests outside of work include playing lead guitar and piano in a cover band and designing/flying radio controlled aircraft.

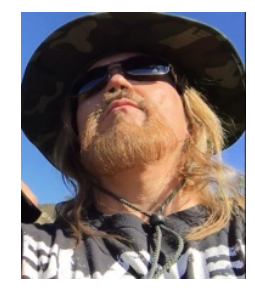

Gary Grayson has supported United States aerospace vehicle and technology programs for over 25 years. He studied combustion under Dr. James T'ien at Case Western Reserve University in Cleveland, Ohio where he received his M.S. and B.S. degrees in fluid and thermal engineering science. At the NASA Lewis Research Center Gary directed a microgravity concurrent-flow flame spread experiment that led to a comprehensive flammability map for thin cellulose fuels. At McDonnell Douglas Mr. Grayson designed the DC-X rocket propellant acquisition system using computational fluid dynamics (CFD) and created propellant slosh and cryogenic thermal stratification analysis tools for the Delta II/III/IV launch vehicles. At Boeing Gary was a technical fellow specializing in propulsion, fluid dynamics, and cryogenics. He improved and validated multiphase cryogenic CFD tools under contract to the NASA Marshall Space Flight Center that enabled prediction of transient cryogenic tank pressure control in variable heating and acceleration environments. Gary directed propulsion system design and analysis on a number of study contracts for Boeing including the NASA Orbital Space Plane, NASA Crew Exploration Vehicle Phase A, NASA Altair Lunar Lander, and the USAF Reusable Booster Program. Mr. Grayson modeled propellant slosh and designed antivortex devices for the NASA Space Launch System program and also for the NASA Constellation Ares I program. Recently, Mr. Grayson led upper stage vehicle design on the DARPA XS-1 Phase I study contract. At the same time he led the team that designed, built, and tested innovative additively manufactured cryogenic check valves and pressurization diffusers. Mr. Grayson has been an instructor at California State University at Long Beach for graduate Rocket and Spacecraft Propulsion. Gary is an AIAA associate fellow with 29 external professional publications including three peer-reviewed journal articles and fifteen patents related to fluid dynamics and thermodynamics. 